\title{
Pelatihan Mindset Sociopreneur dan Aqad Syari'ah Bagi Tenant Fakultas Teknologi Industri Universitas Ahmad Dahlan
}

\author{
Farid Ma'ruf $^{1 *}$, Jefree Fahana ${ }^{2}$, Syifa Fitriani $^{3}$, Amalya Nurul Khairi ${ }^{4}$ \\ Universitas Ahmad Dahlan ${ }^{1,2,3,4}$ \\ farid.maruf@ie.uad.ac.id*, jefree.fahana@tif.uad.ac.id, syifa.fitriani@ie.uad.ac.id, amalya.khairi@tp.uad.ac.id
}

\begin{abstract}
PPK FTI activities is a manifestation of the application of one of the faculty visions, namely entrepreneurship, which is then also supported by ristekbrin through a community service funding scheme. One of the outputs of this activity was to produce 6 viable tenants and became the essential thing in this PPK FTI activity. Several stages were passed, starting from administrative selection until 20 tenants were obtained to participate in the training which would later be selected again into 6 tenants. Sociopreneur mindset training is important in this KDP activity because, in addition to the spirit of empowerment, doing business must also provide benefits to others. In addition, sharia aqad is also a training material because buying and selling aqad is the key to the start of the business process where to be taken. In essence, doing business is about the benefits of the world and savings in the afterlife. Some obstacles were experienced during online training, such as signals and voices, but these did not dampen the tenant's enthusiasm for participating in the training. Most of the tenants were able to receive well and were satisfied with the training material so that it could be practiced in their entrepreneurial activities.
\end{abstract}

Keywords: sociopreneurship; aqad; shariah; training; online.

\begin{abstract}
Abstrak
Kegiatan PPK FTI merupakan wujud pengaplikasian salah satu visi fakultas yakni entrepreneurship kemudian didukung pula oleh ristekbrin melalui skema pendanaan pengabdian. Salah satu luaran dari kegiatan ini adalah menghasilkan 6 tenant yang layak dan menjadi hal yang paling penting dalam kegiatan PPK FTI ini. Beberapa tahapan dilalui mulai dari seleksi administrasi hingga diperoleh 20 tenant untuk mengikuti pelatihan yang nantinya akan diseleksi kembali menjadi 6 tenant. Pelatihan sociopreneur mindset menjadi hal penting dalam kegiatan PPK ini karena disamping semangat pemberdayaan, berbisnis juga harus memberikan manfaat kepada sesama. Selain itu, aqad syariah juga menjadi materi pelatihan karena aqad jual beli merupakan kunci awal proses bisnis mau dibawa kemana. Pada hakikatnya, berbisnis bukan hanya tentang keuntungan dunia, tetapi juga menjadi tabungan kelak di akhirat. Beberapa kendala dialami pada saat pelatihan secara online, seperti sinyal dan suara, tetapi hal tersebut tidak menyurutkan semangat tenant dalam mengikuti pelatihan. Sebagian besar tenant dapat menerima dengan baik dan merasa puas dengan materi yang disampaikan pada saat pelatihan sehingga dapat dipraktikkan dalam kegiatan berwirausahanya.
\end{abstract}

Kata Kunci: sociopreneurship; aqad; syariah; pelatihan; online 


\section{A. PENDAHULUAN}

Dunia usaha pada saat ini banyak diminati oleh semua kalangan, mulai dari yang muda hingga yang tua. Terlebih pada saat pandemi ini, banyak bermunculan wirausaha-wirusaha baru, baik sebagai mata pencaharian utama maupun sampingan karena kegiatan banyak dilakukan di rumah. Jenis usaha yang terus banyak bermunculan saat ini ada di 2 hal, yakni kuliner dan fashion. Kedua jenis bisnis tersebut yang sebelum pandemi ini sudah diprediksi oleh beberapa pihak akan terus bertambah hingga 4-5 tahun yang akan datang.

Fakultas Teknologi Industri Universitas Ahmad Dahlan (FTI UAD) yang salah satu visinya adalah entrepreneurship juga mencoba berperan aktif dalam mengembangkan kewirausahaan. Peran aktif tersebut diwujudkan dengan diperolehnya pendanaan hibah pengabdian dari RISTEKBRIN dengan skema Program Pengembangan Kewirausahaa (PPK). Kegiatan PPK ini diikuti oleh mahasiswa dan alumni FTI UAD, baik yang sudah punya usaha maupun yang akan merintis usaha.

Ada beberapa tahapan yang wajib diikuti oleh 20 tenant tepilih sebelum nantinya akan diseleksi menjadi 6 tenant yang layak, salah satunya adalah pelatihan. Pelatihan ini diselenggarakan secara daring menggunakan platform meeting online yakni zoom. Materi pelatihan yang diberikan merupakan materi yang memang dibutuhkan oleh para tenant untuk menjalankan dan mengembangkan usahanya. Materi tersebut adalah mindset sociopreneur dan akad syariah. Kedua materi tersebut dianggap sebagai dasar dan pondasi dari bisnis yang akan dan telah dijalankan oleh tenant. Kedua materi tersebut disampaikan oleh pemateri yang secara teknik terlibat langsung dengan hal mindset sociopreneur dan aqad syariah.
Berbisnis pada hakekatnya tidak hanya untuk mencari keuntungan untuk diri sendiri dan keluarga, tetapi juga mampu memberikan manfaat untuk sesamanya (Owen, 2017). Semangat PPK FTI UAD dalam menjalankan kegiatan ini adalah semangat sociopreneurship sehingga bisnis yang dicari dan lolos seleksi tentunya bisnis yang mengandung dan menerapkan unsur tersebut. Selain itu, konsep sociopreneurship ini memang sedang menjadi trend saat ini. Sebut saja yang sudah levelnya nasional bahkan internasional ada GoJek, kitabisa.com, tanihub, sweetsunday ice cream, wisata gunung api purba ngelanggeran, dan masih banyak lagi pengusaha-pengusaha yang menerapkan konsep sociopreneur dalam bisnisnya (Yudistia, 2019).

Pada saat ini konsep bisnis seperti ini dapat sangat membantu meningkatkan perekonomian masyaratakat yang terkena dampak pandemi covid-19. Apalagi ditambah dengan banyaknya kampanye "\#ngelarisikoncodewe" di media sosial saat ini semakin meneguhkan bahwa konsep bisnis sociopreneur ini memang diperlukan (Purnomo, 2020). Pelatihan selama 2 jam ini tentang penanaman konsep sociopreneur dalam mindset tenant berharap dapat diaplikasikan ke dalam bisnisnya.

Akad merupakan kunci awal transaksi dari sebuah bisnis dimulai setelah tentunya setelah pondasi mindset sociopreneur ini dibangun. Akad dapat didefinisikan sebagai pertalian ijab dan qabul sesuai dengan kehendak syariat yang berpengaruh pada objek perikatan atau kontrak atau kesekapakatan antara kedua belah pihak (Sholihin, 2013). Kesalahan dalam konsep aqad menyebabkan proses jual beli akan bermasalah. Materi akad yang diberikan dalam pelatihan ini merupakan akad syariah yang sesuai dengan ajaran 
agama Islam. Perkembangan bisnis saat ini menyebabkan konsep akad syariah ini menjadi sedikit agak kabur. Apalagi ditambah dengan hampir semua transaksi jual beli dilakukan menggunakan aplikasi dan jasa kurir. Contoh kasusnya adalah ketika akan membeli barang menggunakan sebuah aplikasi layanan antar dengan model pembayaran langsung kepada drivernya, maka kalau diperhatikan dengan seksama terdapat 2 model akad yang terjadi. Yakni model pertama pemesan berhutang kepada driver layanan antar tersebut untuk membelikan barang yang dipesan kemudian model kedua adalah pemesan membayar kontan kepada driver barang yang dipesan (Sahroni, 2020). Walaupun pada umumnya, secara keseluruhan proses jual beli ini dilakukan secara cash tanpa ada hutang di dalamnya. Tetapi kasus ini tidak akan terjadi ketika pembeli sudah memiliki sejumlah deposit yang ada di aplikasi layanan antar tersebut.

Perkembangan model jual beli yang ada saat ini menuntut juga bagi pelaku bisnis untuk tahu dan lebih memahami proses akad yang terjadi didalamnya. Sepintas memang sepele, tapi pada skala tertentu akad yang tidak jelas bisa menyebabkan masalah yang berujung pada pidana dan tentunya dosa yang akan terbawa sampai meninggal dunia (Wahyudi \& Riduwan, 2020). Sudah jelas dalam Islam bahwa 9 dari 10 pintu rejeki adalah berasal dari perniagaan. Itulah sebabnya akad secara syariah menjadi penting untuk disampaikan sebagai materi pada pelatihan PPK FTI ini. Berbisnis tidak hanya untuk mendapatkan keuntungan di dunia tetapi juga sebagai bekal tabungan menghadap Tuhan Yang Maha Esa kelak.

$$
\text { Adanya kedua materi yang }
$$
disampaikan ini bisa diterapkan dan dijadikan sebagai pondasi serta kunci yang baik dalam berbisnis. Hubungan antara sesama manusia bisa dan hubungan manusia dengan Tuhannya bisa terjaga dengan baik. Selain itu, juga mampu menghindari hal-hal yang masih abu-abu yang muncul ketika menjalankan bisnis ini. Dengan penerapan kedua materi ini ketika bisnis melambung secara Nasional maupun Internasional dapat selalu terjaga dengan baik (Triyanta, 2012).

\section{B. PELAKSAAAN DAN METODE}

Kedua materi pelatihan ini disampaikan selama 2 minggu setiap hari sabtu dengan waktu yang berbeda menyesuaikan dengan narasumber yang diundang. Materi mindset sociopreneur disampaikan oleh Dr. Patisina, CI.CTNLP pada tanggal 27 Juni 2020 pukul 13.00 WIB setelah prosesi pembukaan rangkaian kegiatan PPK FTI ini selesai. Sedangkan materi akad syari'ah disampaikan oleh Dr. Riduwan, S.E., M.Ag. pada tanggal 4 Juli 2020 pukul 08.00 WIB. Lokasi pelatihan awalnya direncanakan di laboratorium kewirausahaan program studi teknik industri kampus 4 Universitas Ahmad Dahlan, tetapi semenjak adanya pandemi Covid-19 bulan Maret 2020 lalu, pelatihan dilaksanakan secara daring menggunakan aplikasi Zoom.

Sebelum hari-H pelaksanaan pelatihan, biasanya 1 atau 2 hari, link dari zoom untuk kegiatan pelatihan PPK FTI ini dibagikan agar bisa dicoba-coba terlebih dahulu sehingga pada saat pelatihan bisa hadir tepat waktu. Link setiap pelatihan pada tiap minggunya selalu berbeda sehingga pemutakhiran informasi selalu disampaikan kepada para tenant. 20 tenant PPK FTI yang mengikuti pelatihan ini beragam, ada yang individu dan ada pula yang berkelompok. Aturan yang ditetapkan oleh tim PPK FTI bahwa seluruh tenant diwajibkan hadir secara online dan kalau tidak bisa wajib ada yang mewakilkan. Kehadiran pada pelatihan ini 
menjadi bentuk tanggung jawab dan konsistensi tenant, serta menjadi salah satu penilaian tim PPK FTI untuk menyaring menjadi 6 tenant lagi. Selain itu, tim PPK FTI selalu mengingatkan akan pentingnya materi yang disampaikan dalam pelatihan ini terlepas dari kewajiban yang harus dilaksanakan oleh tenant PPK FTI yang sudah terpilih.

Pelatihan ini selalu dipandu oleh seorang moderator sebelum narasumber menyampaikan materinya yang kemudian dilanjutkan dengan tanya jawab. Sesi tanya jawab pada tiap pelatihan selalu lebih lama daripada penyampaian materi oleh narasumber. Artinya bahwa antusiasme dan respon tenant dalam mengikuti setiap pelatihan sangat tinggi, baik bagi yang sudah mempunyai usaha maupun yang akan memulai usaha. Diskusi selalu hidup pada sesi tanya jawab, dimana tenant selalu menimpali jawaban dari narasumber untuk menggali lebih dalam lagi konsep dan aplikasi socioprenuer serta akad syari'ah dalam usaha.

Harapan dari 2 materi dalam pelatihan ini adalah dapat memberikan pemahaman yang lebih tentang konsep sociopreneur dan akad syariah dalam sebuah bisnis, apalagi disesuaikan dengan perkembangan saat ini yang sangat cepat dan bisa dikatakan terlalu dinamis. Pada akhir pelatihan, setiap tenant selalu diedarkan 2 link baru, yakni link absensi dan link kuesioner. Link absensi berisi tentang daftar hadir tenant pada setiap pelatihannya sedangkan link kuesioner berisi beberapa pertanyaan seputar kegiatan pelatihan, mulai dari narasumber hingga hambatan pada saat pelatihan. Dari kuesioner yang ada, tim PPK FTI dapat menilai sejauh mana kesuksesan penyelenggaraan kegiatan pelatihan ini.

Karena ini bentuknya pelatihan, tentunya akan ada tugas yang diberikan kepada para tenant setelah semua materi disampaikan. Tugasnya berupa pembuatan rencana bisnis menggunakan Business Model Canvas (BMC) oleh tenant dengan menerapkan materi yang sudah disampaikan. Bagi tenant yang sudah memiliki usaha, bisa juga dengan mengkolaborasikan dengan konsep bisnis yang telah dijalankan sebelumnya.

\section{C.HASIL DAN PEMBAHASAN}

Pelatihan mindset sociopreneur dan akad syariah ini diikuti oleh 20 tenant terpilih. Adapun 20 tenant tersebut adalah sebagai berikut:

Tabel 1. Daftar 20 Tenant

\begin{tabular}{|c|c|c|}
\hline No. & Nama Usaha & Ketua Tim \\
\hline 1. & Mutia Syar'i & Endah Dwi Jayanti \\
\hline 2. & $\begin{array}{c}\text { Si-Doel } \\
\text { Ahmad Dahlan }\end{array}$ & Wardatus Sholihah \\
\hline 3. & Zat_case & Zain Ahmad Taufiq \\
\hline 4. & Jasa PCB & $\begin{array}{l}\text { Ibnu Atma } \\
\text { Kusnandi }\end{array}$ \\
\hline 5. & Eltedirahijab & Dewi Irawati \\
\hline 6. & $\begin{array}{c}\text { FDJ } \\
\text { Engineering }\end{array}$ & M. Furkan \\
\hline 7. & Bening Qalbu & $\begin{array}{c}\text { Daswati Rofiatun } \\
\text { Sahifah, S.T., } \\
\text { M.Pd. }\end{array}$ \\
\hline 8. & Ashiappp Art & Zurara Ryanda \\
\hline 9. & $\begin{array}{c}\text { Okeanos } \\
\text { Herbal Laut }\end{array}$ & $\begin{array}{l}\text { Afif Salaf } \\
\text { Asshidiqi }\end{array}$ \\
\hline 10 & $\begin{array}{c}\text { Dermayu } \\
\text { Catering Jogja }\end{array}$ & Waryo \\
\hline 11. & $\begin{array}{l}\text { Ngumbang } \\
\text { Tapak }\end{array}$ & $\begin{array}{c}\text { Baharsyaikh Aulia } \\
\text { H }\end{array}$ \\
\hline 12. & $\begin{array}{l}\text { Konveksi dan } \\
\text { Percetakan }\end{array}$ & $\begin{array}{c}\text { Danis Wibawa, } \\
\text { S.T. }\end{array}$ \\
\hline 13. & Bengkel Las & Adhi Susatyo \\
\hline 14. & Zpediaku & Saiful Hadi \\
\hline 15. & $\begin{array}{c}\text { Muvon } \\
\text { Multimedia }\end{array}$ & Rio \\
\hline
\end{tabular}




\begin{tabular}{ccc}
\hline No. & Nama Usaha & Ketua Tim \\
\hline 16. & $\begin{array}{c}\text { Martabak } \\
\text { Manis }\end{array}$ & Risang Ghani \\
\hline 17. & $\begin{array}{c}\text { Chicken } \\
\text { Lemon }\end{array}$ & Vicko \\
\hline 18 & $\begin{array}{c}\text { Mesin Tetas } \\
\text { Telor }\end{array}$ & Wildan \\
\hline 19. & Printing Kaos & Githo \\
\hline 20. & $\begin{array}{c}\text { Clythoria } \\
\text { Yoghurt }\end{array}$ & Yanas \\
\hline
\end{tabular}

Dari 20 tenant tersebut dapat diklasifikasikan berdasarkan kategori bisnisnya menjadi 15\% kategori fashion, 5\% kategori seni, 20\% kategori kuliner, 5\% kategori aplikasi, 50\% kategori desain produk, dan 5\% kategori video. Pembagian kategori ini berdasarkan rencana stategis badan ekonomi kreatif Republik Indonesia tahun 2015-2019 yang pada periode saat ini menjadi satu dengan kementerian pariwisata dan ekonomi kreatif di bawah kepemimpinan bapak Wisnutama (Munaf, 2017). Semua tenant ini wajib mengikuti pelatihan secara online menggunakan aplikasi zoom.

Pelatihan pertama dengan materi mindset sociopreneur ini membahas konsep mindset mulai dari struktur otak manusia hingga prinsip sosial yang dimasukkan ke dalam sebuah bisnis. Narasumber memulai pelatihan dengan terlebih dahulu memberikan contoh studi kasus tentang kutu anjing yang dimasukkan ke dalam kotak korek api selama 1 minggu, kemudian melihat apa yang akan terjadi (Williams, 2019). Contoh kasus ini bertujuan untuk membuka pemikiran dan logika para tenant agar melihat sesuatu lebih luas lagi, khususnya bisnis. Ketika masuk ke dunia bisnis, mulai dihilangkan kata-kata siapa dan apa, tetapi perbanyaklah kata-kata bagaimana. Karena dalam berbisnis, seorang pemilik usaha tidak akan bisa menjalankan usahanya tanpa orang lain. Lebih mendalam lagi, narasumber menyampaikan bagaimana menyeimbangkan kinerja otak, emosi, dan fisik dalam mengembangkan bisnisnya sehingga bisnis dapat berjalan efektif dan efisien.

Satu formula yang disampaikan oleh narasumber Dr. Patisina tentang bagaimana menjadi entrepreneur sukses adalah dengan mengkombinasikan antara faktor manusia, lingkungan, dan Tuhan YME. Faktor manusia disini dapat digambarkan sebagai sebuah segitiga sama sisi yang saling berhubungan timbal balik dengan 3 aspek didalamnya, yakni tujuan, usaha mewujudkan tujuan tersebut, dan apa yang akan dihasilkan ketika tujuan tersebut tercapai. Faktor lingkungan yang dimaksud disini adalah kemampuan manusia untuk membaca peluang yang ada dan tentunya mendapat dukungan dari lingkungan sekitar, minimal keluarga. Faktor yang terakhir ini merupakan faktor penentu dari semua usaha yang telah dilakukan, yakni faktor keTuhanan. Di faktor ini sehebat, sepintar, dan sejenius apapun seorang pebisnis menjadi tidak ada gunanya ketika Tuhan tidak berkehendak atas hal tersebut. Selain itu, di faktor ini semua pebisnis memantaskan diri di hadapan Tuhan agar semua yang telah dilakukan dapat restu dan rahmat-Nya. Salah satu cara memantaskan diri adalah dengan berbagai dan memberi manfaat kepada sesama. Di sinilah unsur sociopreneur dapat diaplikasikan (Patisina, 2019).

Pada akhir materi, narasumber Dr Patisina berpesan kepada para tenant untuk bisa mempraktikkan mindset sociopreneur ini dengan menetapkan hasilnya bagaimana, semangat, senantiasa melibatkan VAKOG (Visual, Auditory, Kinesthetic, Olfactory, Gustatory), mengaktifkan visualisasi dan alam bawah sadar, serta lakukan semua hal tersebut secara berulang. Tanggapan beragam muncul dari para tenant setelah 
materi ini disampaikan, diantaranya dalam membangun usaha tidak hanya kerja keras semata, tetapi juga ada campur tangan Tuhan Yang Maha Esa disitu, selalu berfikir positif dengan mengubah apa menjadi bagaimana, konsisitensi pada hasil menjadi hal yang harus difokuskan dalam mengembangkan usaha, dan lain-lain. Tanggapan tersebut berdasarkan hasil kuesioner dari link yang sudah dibagikan oleh Tim PPK FTI kepada para tenant setelah selesai mendengarkan penjelasan dari narasumber.

Berdasarkan kuesioner pula diperoleh hasil bahwa narasumber Dr Patisina dapat menyampaikan materinya dengan baik. Selain itu, para tenant juga dapat memahami materi yang disampaikan oleh narasumber.

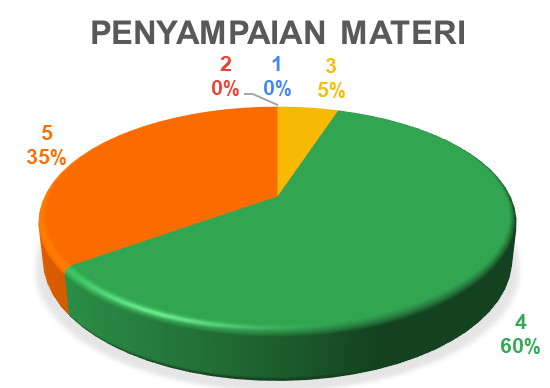

Gambar 1. Respon Terhadap Penyampaian Materi

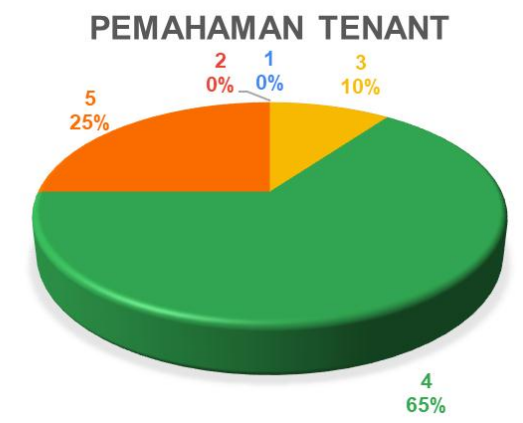

Gambar 2. Respon Tentang Pemahaman Tenant

Pelatihan berikutnya diselenggarakan pada minggu berikutnya di hari yang sama tetapi pada jam yang berbeda. Materi pelatihannya adalah tentang akad syari'ah. Pelatihan pada minggu kedua ini dibuka terlebih dahulu oleh seorang moderator kemudian dilanjutkan dengan penyampaian materi oleh narasumber dan diakhiri dengan diskusi serta tanya jawab. Akad merupakan hal penting dalam proses dan transaksi jual beli karena akad bisa disebut sebagai kunci pembuka transaksi jual beli nanti akan bagaimana dan berakhir bagaimana. Akad yang sesuai dengan syari'at Islam tentunya akan membawa keberkahan dalam proses jual beli yang akan dilakukan.

Di samping itu, akad yang baik juga akan memberikan keuntungan bagi pebisnis tentunya. Karena berbicara akad syari'ah, maka narasumber ust Riduwan mengawali materinya dengan menjelaskan tentang dasar ayat $\mathrm{Al}-\mathrm{Qu}$ 'ran dan Hadits yang menjelaskan tentang muamalah dalam Islam, termasuk di dalamnya perihal ekonomi hingga jual beli yang diperbolehkan dalam Islam. Akad syari'ah merupakan bagian dari proses ekonomi syari'ah yang tujuannya adalah mampu mewujudkan kesuksesan yang hakiki. Kesuksesan yang hakiki merupakan tingkat ketercapaian kesejahteraan yang didalamnya terdapat unsur kebahagiaan secara spiritual dan kemakmuran secara material, baik pada individu maupun masyarakat. Konsep dasar ekonomi syari'ah mengajarkan bahwa yang diuntungkan dari sebuah bisnis tidak hanya individu pebisnisnya tetapi juga memberikan manfaat bagi masyarakat.

Narasumber juga menyampaikan dalam materinya bahwa ada 3 pilar dalam ekonomi syari'ah yakni berkeadilan, berkesinambungan, dan kemaslahatan. Selain 3 pilar, juga ada istilah fondasi ekonomi syari'ah. Fondasi ekonomi syari'ah ini antara lain (1) meletakkan tata hubungan bisnis dalam hal ukhuwah Islamiyah untuk kesejahteraan Bersama, (2) kaidah hukum muamalah dalam bidang ekonomi syari'ah menjadikan pedoman dalam kegiatan perekonomian agar sesuai dengan syari'at 
Islam, (3) akhlak yang baik dalam membangun aktivitas bisnis menjadi pagar agar sesuai dengan syari'at Islam, dan (4) semua yang manusia lakukan selalu akan berakhir pada keputusan Tuhan Yang Maha Esa sehingga manusia memiliki akutabilitas ketuhanan layaknya good corporate governance dan market discipline. Penyampaian materi menjadi menarik ketika interupsi dari tenant untuk menanggapi.

Di dalam syari'at Islam terdapat beberapa jenis jual beli yang diajarkan. Adapun jenis jual beli tersebut antara lain murabaha, salam, istishna, tauliyah, wadi'ah, isyraq, mustarsal, muzayadah, muajjal, muayyadah, dan lain-lain (Priyono; Zainuddin, 2016). Oleh karena itu, seorang pebisnis harus mengetahui konsep bisnisnya bagaimana sehingga akad yang akan digunakan juga sesuai. Seperti dicontohkan oleh narasumber tentang muayyadah atau bisa disebut sebagai barter. Kalau bisnisnya berupa tukar-menukar barang tentunya akadnya dilengkapi pula spesifkasi barang yang boleh ditukarkan sehingga sudah jelas diawal. Sebagai penutup, narasumber Dr Riduwan memberikan kesimpulan bahwa akad diawal harus jelas, transparan, dan sesuai dengan jenis jual belinya karena hal tersebut akan berpengaruh tidak hanya pada keuntungan semata tetapi pada keberkahannya.

Setelah pemaparan materi, sesi berikutnya adalah diskusi dan tanya jawab walau kenyataannya sudah dilakukan pada saat penyampaian materi berlangsung. Beberapa pertanyaan yang muncul pada pelatihan akad syari'ah ini antara lain akad jual beli dengan model reseller, dropship, dan sejenisnya itu bagaimana, jual beli dengan sistem tender karena merupakan proyek pemerintah bagaimana, dan lain-lain. Dr Riduwan menjawab pada hakikatnya ketika akad diawal sudah jelas dan unsur suka sama suka itu terjadi, proses jual beli insya Allah berkah. Yang dimaksud akad sudah jelas disini, mulai dari sistem pembayaran kontan atau menyicil, kalau sistem cicilan jangan sampai ada unsur riba disitu, perjanjian bermaterai jika jumlah nominalnya banyak, kriteria barang disampaikan dengan jujur, hingga waktu produksi juga disampaikan. Sehingga ketika semuanya sudah transparan dan akuntabel, masalah-masalah yang akan terjadi di kemudian hari dapat dihindari.

Pada pelatihan tentang akad syariah ini respon tenant sangat baik mulai dari penyampaian materi oleh narasumber yang mudah dipahami, materi yang disampaikan aplikatif, dan sesi tanya jawab yang memuaskan para tenant. Secara grafik hasil kuesioner tersebut dapat dilihat pada gambar di bawah ini:

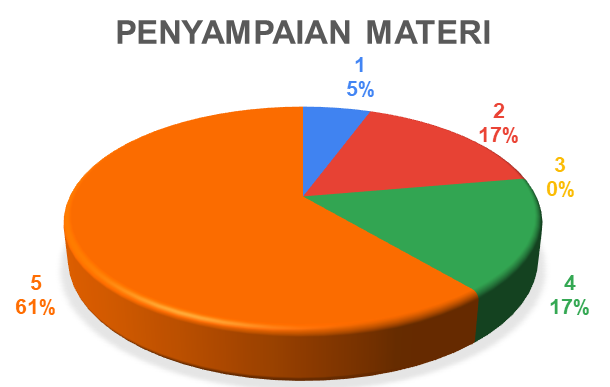

Gambar 3. Penyampaian Materi

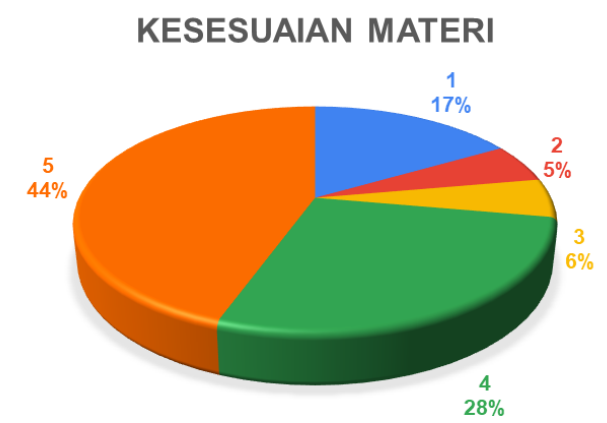

Gambar 4. Kesesuaian Materi dengan Harapan 


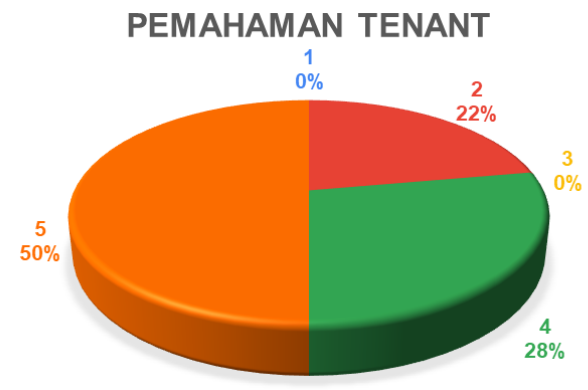

Gambar 5. Pemahaman Tenant Terhadap Materi

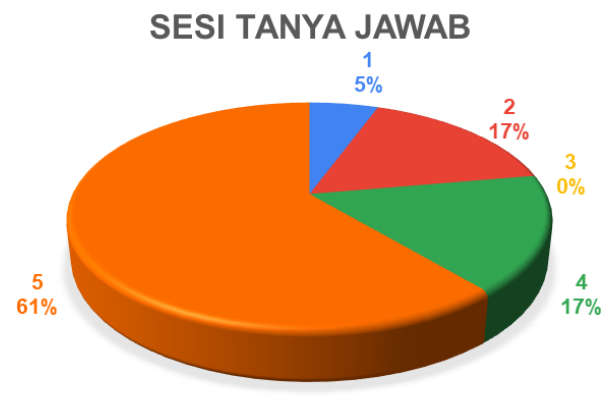

Gambar 6. Efektifitas Tanya Jawab

Ada sedikit perbedaan dengan hasil kuesioner pada pelatihan pertama tentang mindset sociopreneur. Kuesioner pada pelatihan ini terdapat 2 item pertanyaan yang ditambahkan sebagai hasil evaluasi tim PPK FTI terhadap pelatihan pertama. Sedikit penjelasan mengenai angka 1,2,3,4, dan 5 pada gambar di atas adalah bahwa pada kuesioner ini menggunakan skala likert. Artinya, angka 1 berarti sangat tidak setuju, angka 2 berarti tidak setuju, angka 3 berarti cukup setuju, angka 4 berarti setuju, dan angka 5 berarti sangat setuju.

Selama 2 kali pelatihan tentunya ada kendala yang muncul. Apalagi pelatihaannya diselenggarakan secara daring melalui lokasi masing-masing tenant yang secara otomatis juga berbeda karakternya karena pandemi saat ini. Kendala yang sering muncul dan terjadi adalah kuota, sinyal, kualitas suara, dan kualitas gambar. Masalah kuota dapat terselesaikan karena setiap tenant akan mendapatkan jatah kuota dari tim PPK FTI selama pelatihan berlangsung, dengan syarat hadir selama pelatihan. Untuk masalah sinyal, suara, dan gambar memang tetap jadi kendala, tetapi hal ini tidak menyurutkan semangat tenant untuk tetap mengikuti pelatihan. Alhasil, setiap pelatihan ada 2-3 tenant yang harus keluar masuk aplikasi zoom karena masalah tersebut. Secara grafik hasil kuesioner tentang kualitas suara dan gambar dapat dilihat pada gambar di bawah ini:

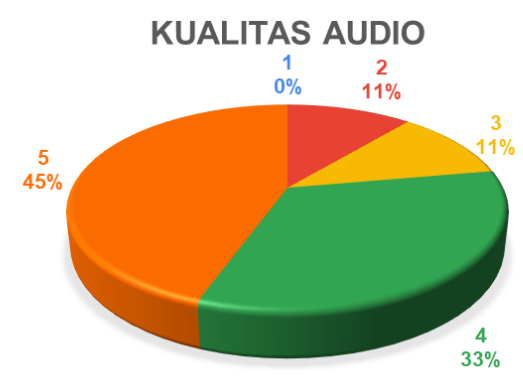

Gambar 7. Kualitas Audio

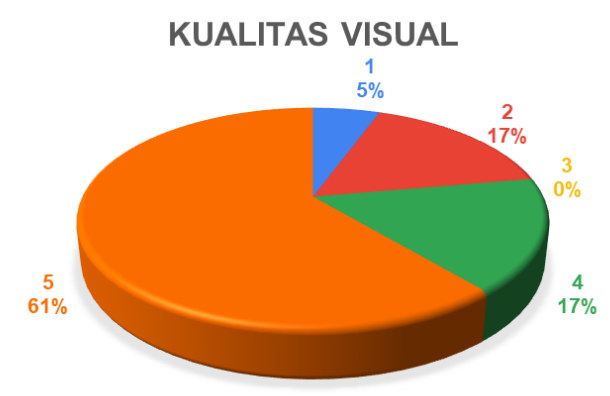

Gambar 8. Kualitas Gambar

Pelatihan secara online ini ternyata juga membutuhkan dukungan perangkat komputer, notebook, atau HP yang bagus. Beberapa tenant menyampaikan juga secara sinyal, suara, dan gambar sudah bagus, tetapi tiba-tiba notebook macet dan panas. Setelah didiamkan beberapa saat notebook kembali normal dan bisa bergabung pelatihan secara online kembali. Kendala lain yang muncul adalah waktu pelatihan yang kadang berbarengan dengan waktu kerja para tenant, tetapi di sisi lain waktu narasumber juga tidak kalah sibuknya. Solusi untuk pemilihan 
waktu ini adalah tetap menyesuaikan waktu narasumber dan para tenan diberikan kelonggaran untuk keluar masuk pada saat pelatihan atau bisa mewakilkan kepada anggota timnya, khususnya yang berkelompok.

\section{PENUTUP}

\section{Simpulan}

Pelatihan mindset sociopreneur dan akad syari'ah ini dapat diterima dengan baik oleh para tenant. Selain itu, kedua pelatihan ini mampu memberikan tambahan wawasan dalam menjalankan sebuah bisnis. Bisnis harus dilandasi agama agar perjalanannya berkah dan barokah.

\section{Saran}

Setelah kedua pelatihan ini selesai masih dilanjutkan dengan 2 pelatihan lagi dengan materi yang berbeda. Kedua pelatihan ini terdiri dari 4 materi yakni manajemen keuangan, desain produk, legal dan branding, serta digital marketing. Selain itu, setelah semua kegiatan pelatihan selesai, semua tenant akan diberi penugasan untuk mengaplikasikan materi yang telah didapat ke dalam sebuah rencana bisnis.

\section{Ucapan Terima Kasih}

Terima kasih diucapkan kepada RistekBRIN sebagai pemberi dana kegiatan pengabdian multi tahun dengan skema Program Pengembangan Kewiraushaaan Fakultas Teknologi Industri Universitas Ahmad Dahlan (PPK FTI UAD). Selain itu, juga dihaturkan kepada Lembaga Penelitian dan Pengabdian Masyarakat Universitas Ahmad Dahlan (LPPM UAD) yang sudah mambantu tim PPK FTI ini hingga lolos pendanaan.

\section{E. DAFTAR PUSTAKA}

Munaf, T. (2017). Rencana Strategis Badan Ekonomi Kreatif 2015-. In Badan Ekonomi Kreatif (Vol. 1). Jakarta.

Owen, J. (2017). The Mindset of Success: Accelerate Your Career from Good Manager to Great Leader. Kogan Page Publishers.

Patisina. (2019). Pensiun Preneurship (1st ed.; H. Rahmawan, ed.). Yogyakarta: Semesta Ilmu.

Priyono; Zainuddin, I. (2016). Teori Ekonomi (2nd ed.; T. Chandra, ed.). Sidoarjo: Zifatama Publishing.

Purnomo, D. I. A. (2020). Jangan Lelah Berproses (I; M. D. K. S. Azuzah, ed.). Jakarta: PT Serambi Ilmu Semesta.

Sahroni, O. (2020). Fikih Muamalah Kontemporer: Jilid 3. Jakarta: Republika Penerbit.

Sholihin, A. I. (2013). Buku pintar ekonomi syariah. Gramedia Pustaka Utama.

Triyanta, A. (2012). Hukum Ekonomi Islam "Dari Politik Hukum Ekonomi Islam Sampai Pranata Ekonomi Syariah” (I; N. Huda, ed.). Yogyakarta: FH UII Press.

Wahyudi, R., \& Riduwan. (2020). BAYANI (1st ed.; H. Rahmawan, ed.). Yogyakarta: UAD Press.

Williams, E. (2019). I Heart My Life: Discover Your Purpose, Transform Your Mindset, and Create Success Beyond Your Dreams. Hay House, Inc.

Yudistia, A. (2019). Become Rich As A Sociopreneur (1st ed.; L. Irawati, ed.). Jakarta: PT Grasindo. 